Landslides (2019) 16:125-126 DOI 10.1007/s10346-018-1094-x Published online: 14 December 2018 (c) Springer-Verlag GmbH Germany part of Springer Nature 2018

Correction to: Landslides

https://doi.org/10.1007/s10346-018-1071-4

The published version of this article, unfortunately, contained error. A compass went unconverted in the upper-right corner of Fig. 1. Given in this article is the correct image. The original article has been corrected.

The online version of the original article can be found at https://doi.org/10.1007/s10346018-1071-4

L.-q. Li · N.-p. Ju $(-a) \cdot$ S. Zhang $\cdot X_{\text {. }}-x_{0}$ Deng

State Key Laboratory of Geohazard Prevention and Geoenvironment Protection,

Chengdu University of Technology,

Chengdu, 610059, China

Email:287820171@qq.com

L.-q. Li

e-mail: lilongqi1986@gmail.com

S. Zhang

e-mail: 1164553606@qq.com

X.-x. Deng

e-mail: 975640886@qq.com

L.-q. Li · D. Sheng

ARC Centre of Excellence for Geotechnical Science and Engineering,

The University of Newcastle,

Callaghan, NSW 2308, Australia

D. Sheng

e-mail: daichao.sheng@newcastle.edu.au

\title{
Correction to: Seismic wave propagation characteristic
and its effects on the failure of steep jointed anti-dip \\ Correction to: Seismic wave propagation characteristic
and its effects on the failure of steep jointed anti-dip rock slope \\ Long-qi Li · Neng-pan Ju · Shuai Zhang · Xiao-xue Deng · Daichao Sheng
}




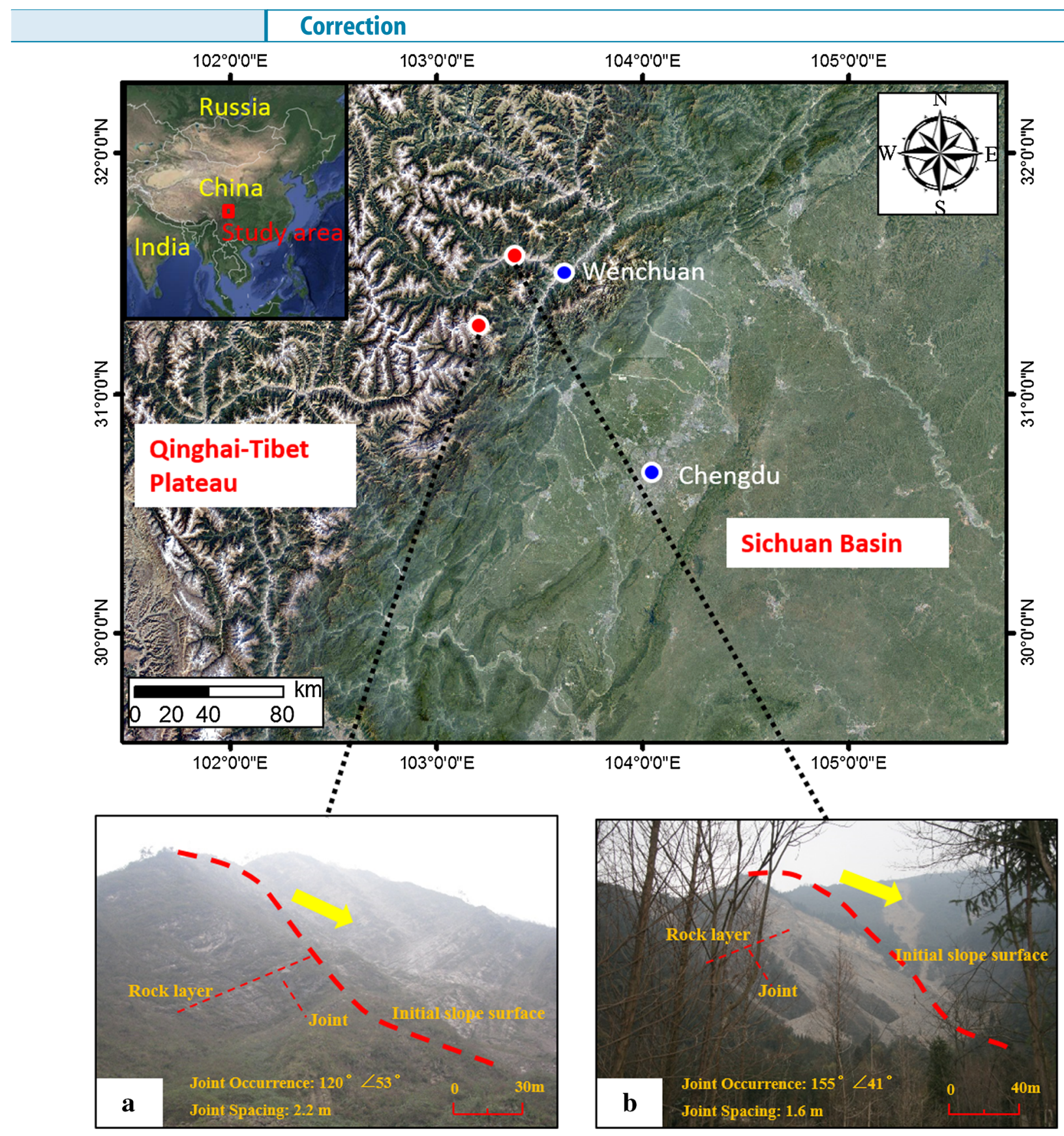

Fig. 1 Two kinds of anti-dip rock slope failure cases: a Jianshan landslide. b Heifengkou landslide 